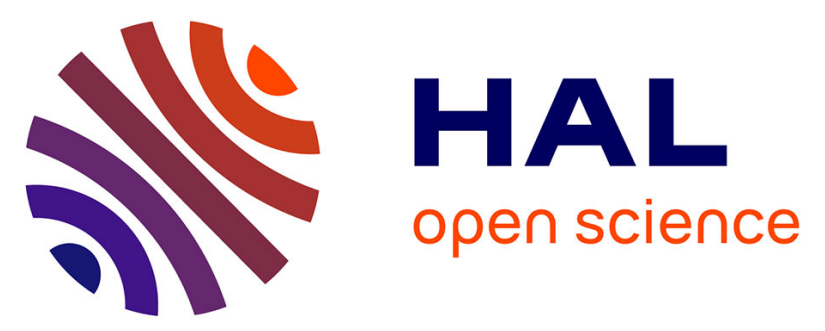

\title{
Impact of the Replacement of a Triphenylamine by a Diphenylmethylamine Unit on the Electrochemical Behavior of Pentaerythritol-Based Push-Pull Tetramers
}

Claudia Malacrida, Amir Hossein Habibi, Sergio Gámez-valenzuela, Illia Lenko, Pablo Simón Marqués, Antoine Labrunie, Jérémie Grolleau, Juan

López navarrete, M. Carmen Ruiz delgado, Clément Cabanetos, et al.

\section{To cite this version:}

Claudia Malacrida, Amir Hossein Habibi, Sergio Gámez-valenzuela, Illia Lenko, Pablo Simón Marqués, et al.. Impact of the Replacement of a Triphenylamine by a Diphenylmethylamine Unit on the Electrochemical Behavior of Pentaerythritol-Based Push-Pull Tetramers. ChemElectroChem, 2019, 6 (16), pp.4215-4228. 10.1002/celc.201900565 . hal-02327115

\section{HAL Id: hal-02327115 \\ https://hal.science/hal-02327115}

Submitted on 4 Jan 2021

HAL is a multi-disciplinary open access archive for the deposit and dissemination of scientific research documents, whether they are published or not. The documents may come from teaching and research institutions in France or abroad, or from public or private research centers.
L'archive ouverte pluridisciplinaire HAL, est destinée au dépôt et à la diffusion de documents scientifiques de niveau recherche, publiés ou non, émanant des établissements d'enseignement et de recherche français ou étrangers, des laboratoires publics ou privés. 


\section{Impact of the replacement of a triphenylamine by a diphenylmethylamine unit}

\section{on the electrochemical behavior of pentaerythritol-based push-pull tetramers}

Claudia Malacrida, ${ }^{1}$ Amir Hossein Habibi, ${ }^{2}$ Sergio Gámez-Valenzuela, ${ }^{3}$ Illia Lenko, ${ }^{2}$ Pablo Simón Marqués, ${ }^{2}$ Antoine Labrunie, ${ }^{2}$ Jérémie Grolleau, ${ }^{2}$ Juan T. López Navarrete, ${ }^{3}$ M. Carmen Ruiz Delgado, ${ }^{3}$ Clément Cabanetos, ${ }^{2 *}$ Philippe Blanchard, ${ }^{2 *}$ Sabine Ludwigs ${ }^{1 *}$

Address 1: IPOC-Functional Polymers, Institute of Polymer Chemistry, University of Stuttgart, Pfaffenwaldring 55, 70569 Stuttgart, Germany

Address 2: MOLTECH-Anjou, UMR 6200, UNIV Angers, CNRS, 2 bd Lavoisier, 49045 ANGERS Cedex, France

Address 3: Department of Physical Chemistry, University of Málaga, 29071 Málaga, Spain

Corresponding authors: sabine.ludwigs@ipoc.uni-stuttgart.de, clement.cabanetos@univ-angers.fr, philippe.blanchard@univ-angers.fr

Keywords - crosslinking, electrochemistry, polymer, push-pull molecules, radical ions

Abstract: The synthesis of a tetra-functionalized pentaerythritol core decorated with $N$-methyl- $N, N$ diphenylamine-based push-pull chromophores and its electropolymerization to 3D push-pull networks are described. The electrochemical and absorption behaviors of the tetramer are compared with the one of two reference linear push-pull compounds, carrying triphenylamine (TPA) or methyldiphenylamine (MeDPA) donor groups, a thienyl linker and a dicyanovinyl acceptor group (DCV). We found that substituting the outer phenyl with a methyl group causes important differences in the radical cation stability, such that MeDPA chromophore generates stable dimers and TPA is reversibly oxidized. Interestingly, DFT calculations suggest that steric hindrance and electrostatic interactions dominate the radical cation reactivity.

\section{Introduction}

Triphenylamine (TPA) and more generally arylamine derivatives, constitute outstanding building blocks for the preparation of electroactive materials for opto-electronic applications. ${ }^{[1-3]}$ In particular, D- $\pi$-A push-pull molecules, in which the electron-donating group (D) derived from an arylamine is connected to an electronwithdrawing group (A) through a $\pi$-conjugated spacer, have been extensively investigated as efficient donor materials for organic photovoltaics (OPV) ${ }^{[4-10]}$ and electro-optical applications ${ }^{[11,12]}$. On the other hand, arylamine derivatives may exhibit a peculiar electrochemical behavior resulting in the molecule dimerization triggered by their chemical oxidation. ${ }^{[13-16]}$ The electrochemically generated electroactive benzidine-based dimers, endowed with a biphenyl bond, are also generally soluble and diffuse from the 
working electrode to the electrolyte solution. ${ }^{[17]}$ Electropolymerizable arylamine containing monomers can be achieved by exploiting the dimerization ability of two or more unsubstituted arylamine units connected to a central core, for example in star-bust or multimeric systems. Different examples of electropolymerization of arylamine derivatives to produce modified electrodes are indeed reported in the literature, ${ }^{[18-23]}$ and have shown promising results when employed as electroactive polymer layers in electrochromic devices. ${ }^{[20-24]}$ Another attractive approach for the obtainment of functionalized triarylamine electroactive surface, as an alternative to electrodeposition from monomer solution, exploits the dimerizing ability of arylamine units just in a post deposition step of pre-deposited films. In this case the triarylamine unit is present for example as a redox-active pendant covalently bound to a polymer backbone, acting as a cross-linker unit upon oxidative triggering, and generating polymer films crosslinked with redox-active tetraphenylbenzidine (TPB) moieties. ${ }^{[1,25-27]}$

While the redox behavior of simple arylamines upon oxidation is known and well-characterized, their functionalization by $\pi$-conjugated blocks, such as in the case of $D-\pi$-A push-pull molecules, results in an enhanced charge delocalization of the radical-cation species that might lead to a different electrochemical behavior. In this general context, we previously showed that the simple and synthetically accessible TPAbased push-pull molecule 1 (2-((5-(4-(diphenylamino)phenyl)thiophen-2-yl)methylene)malononitrile) (Scheme 1) exhibited good absorption properties in the visible spectrum and interesting photovoltaic properties as donor material combined with $\mathrm{C}_{60}{ }^{[10,28,29]}$ or its soluble analogue [6,6]-phenyl-C 61 -butyric acid methyl ester $\left(\mathrm{PC}_{61} \mathrm{BM}\right)$ as acceptors. ${ }^{[30]}$ More recently, following a "multimer" approach, the related pentaerythritol based push-pull tetramer Tetra-1 was shown to give promising and higher power conversion efficiencies (PCEs) when blended with $\mathrm{PC}_{71} \mathrm{BM}$ in bulk heterojunction solar cells. ${ }^{[31]}$ In addition, the substitution of one terminal phenyl ring of the TPA unit of molecule 1 by a methyl group affording 2 (2((5-(4-(methyl(phenyl)amino)phenyl)thiophen-2-yl)methylene)malononitrile), induced a 50-fold increase of hole mobility hence resulting in better photovoltaic properties. ${ }^{[32]}$

Based on these results, the analogue of Tetra-1 bearing methyldiphenylamine (MeDPA) units instead of TPA, namely Tetra-2, has been synthesized herein. The optical and electrochemical properties of Tetra-2 together with reference compounds 1, 2 and Tetra-1 have been analysed by UV-vis spectroscopy and cyclic voltammetry. The different electrochemical behaviour of model compounds $\mathbf{1}$ and $\mathbf{2}$ is elucidated through in-situ spectroelectrochemical experiments and DFT calculations. The specific electrochemical coupling of Tetra-2 is utilized to generate 3D-push-pull networks on electrode surfaces through oxidative electropolymerization. The so synthetized electroactive 3D-push-pull network of Tetra-2 have been then characterized by means of cyclic voltammetry and in-situ spectroelectrochemistry. 

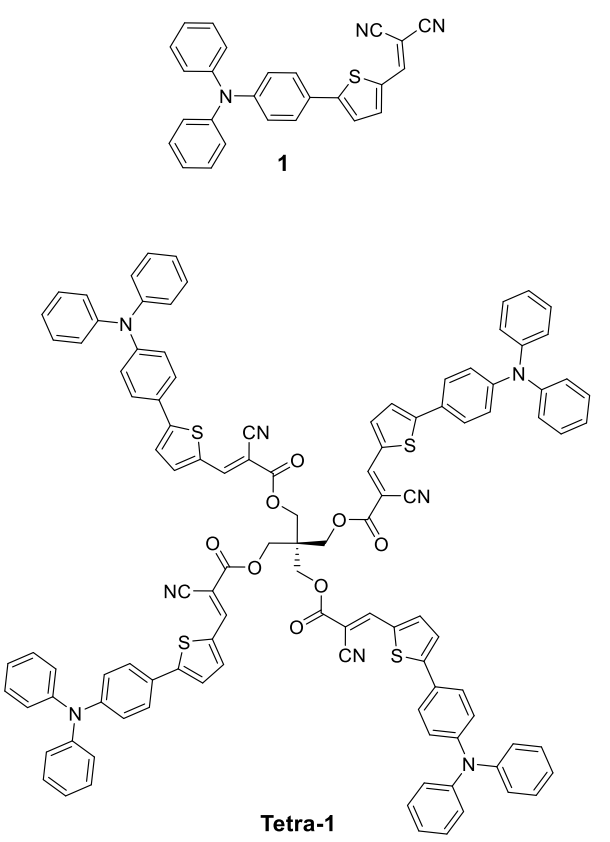
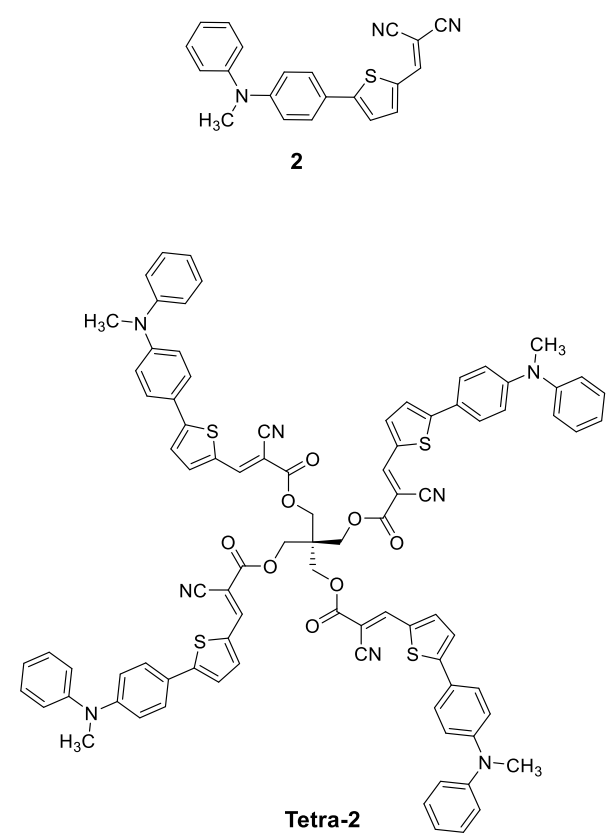

Scheme 1. Structure of push-pull monomers 1 and 2; Tetra-1 and new tetramer Tetra-2

\section{Results and Discussion}

Synthesis. Reference push-pull molecules $\mathbf{1}^{[28]}$ and $2^{[32]}$ have been prepared according to literature procedures. Following the same strategy recently developed for Tetra $1,{ }^{[31]}$ the new molecular target Tetra2 was synthesized in 54\% yield by a Knœvenagel polycondensation between an excess of aldehyde 3 and the pentaerythritol derivative $4^{[31]}$ containing four activated methylene groups (Scheme 2). This lower yield as compared to that of Tetra-1 (80\% yield), is mainly due to the lower solubility of Tetra-2 and intermediated reaction compounds and difficulties associated with its purification.

Thus, the key intermediate aldehyde $\mathbf{3}$ was synthesized using an already reported procedure based on a sequence of successive Stille and Vilsmeier-Haack reactions starting from 4-bromo- $N$-methyl- $N$ phenylaniline 5. ${ }^{[32]}$ In order to get rid of the toxic tributyl(thiophene-2-yl) stannane reagent used previously, alternative synthetic routes to $\mathbf{3}$ were tested. A direct heteroarylation between bromo compound $\mathbf{5}$ and 2thiophenecarboxaldehyde led to 3 only in $21 \%$ yield. Better results were obtained by using the Suzuki conditions. Whereas reaction between (5-formylthiophen-2-yl)boronic acid and $\mathbf{5}$ gave a modest yield of $60 \%$, the Suzuki coupling between the boronic acid 7 and 5-bromothiophene-2-carbaldehyde under microwaves activation was much more efficient affording aldehyde 3 in $95 \%$ yield. 


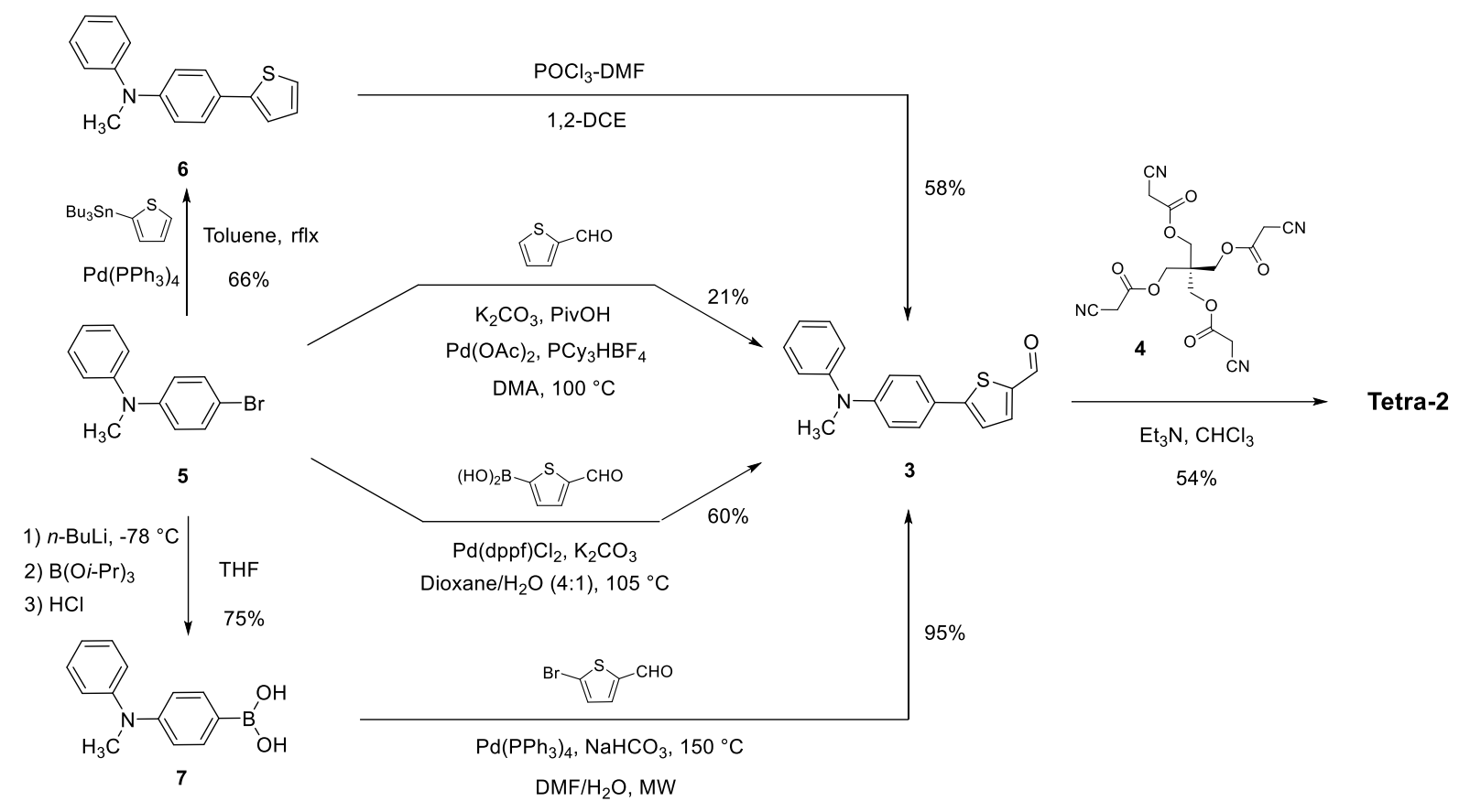

Scheme 2. Synthetic routes to Tetra-2

Compared to its TPA analogue Tetra-1, ${ }^{[31]}$ Tetra-2 exhibits a significantly lower solubility in dichloromethane or chloroform due to the replacement of one external phenyl ring by a methyl group for each push-pull moiety. However, Tetra-2 was successfully characterized by ${ }^{1} \mathrm{H}$ NMR spectroscopy in deuterated 1,1,2,2-tetrachloroethane, infrared spectroscopy and mass spectrometry (Figure S1 in the supporting information).

Electronic properties. The absorption properties of the known molecules 1, 2 and Tetra-1 and those of the new target Tetra-2 have been analyzed by UV-vis spectroscopy in the same conditions in $c a .10^{-5} \mathrm{M}$ dichloromethane solutions and as thin-films. Typically, thin-films on glass were obtained by spin-casting (speed rate $1300 \mathrm{rpm}$ ) a $10 \mathrm{mg} / \mathrm{mL}$ solution of titled compounds in chloroform, except for Tetra-2 for which a mixture of chloroform and 1,1,2,2-tetrachloroethane $(9: 1 \mathrm{v} / \mathrm{v})$ was used for solubility reasons allowing for the preparation of more homogenous thin-films. Table 1 gathers the absorption properties of all compounds. The optical bandgaps were estimated from their absorption onsets at low energy. 
Table 1. Absorption properties in solution and in the solid-state

\begin{tabular}{ccccc}
\hline Compound & $\begin{array}{c}\lambda_{\max }(\mathbf{n m}) \\
\mathbf{C H}_{\mathbf{2}} \mathbf{C l}_{\mathbf{2}}\end{array}$ & $\boldsymbol{\varepsilon}\left(\mathbf{M}^{\mathbf{- 1}} \mathbf{c m}^{-\mathbf{1}}\right)$ & $\begin{array}{c}\lambda_{\max }(\mathbf{n m}) \\
\text { Thin-Film }\end{array}$ & $\boldsymbol{E}_{\mathbf{g}}{ }^{\text {opt }}(\mathbf{e V})$ \\
\hline $\mathbf{1}$ & 501 & 33900 & 523 & 1.98 \\
Tetra-1 & 489 & 132000 & 483 & 1.98 \\
Tetra-2 & 486 & 138000 & 493 & 2.02 \\
\hline
\end{tabular}

Figure $1(\mathrm{a}, \mathrm{b})$ shows that push-pull monomers 1 and $\mathbf{2}$ exhibit a main broad and intense internal charge transfer (ICT) band with the same absorption maximum of $\lambda_{\max }$ at $501 \mathrm{~nm}$. Tetra-1 and Tetra-2 also show an ICT band with similar $\lambda_{\max }$ of $489 \mathrm{~nm}$ and $486 \mathrm{~nm}$, respectively. Compared to reference push-pull molecules 1 and 2, the hypsochromic shift recorded for Tetra-1 and Tetra-2 results from the replacement of the DCV group of each push-pull moiety by the less electron-withdrawing cyanoacrylate ester group (Figure 1, bottom). As expected, the molar extinction coefficients $\varepsilon$ of the push-pull tetramers are approximately four times higher than those of the corresponding monomers.

Compared to solutions (Figure $1 \mathrm{c}$ and d), the ICT band of thin-films of Tetra-1 and Tetra-2 is broadened in agreement with the existence of $\pi-\pi$ intermolecular interactions in the solid state. However, contrary to the $6 \mathrm{~nm}$ hypsochromic shift observed for thin-films of Tetra-1, ${ }^{[31]}$ the passage from the solution to the solid-state leads to a bathochromic shift of the absorption maximum of Tetra-2 from $486 \mathrm{~nm}$ to $493 \mathrm{~nm}$, suggesting different packing properties. The optical bandgap of Tetra-2 was estimated from the onset of absorption at low energy $\left(\lambda_{\text {onset }}=612 \mathrm{~nm}\right)$ leading to a value $E_{\mathrm{g}}{ }^{\text {opt }}$ of $2.02 \mathrm{eV}$. It is interesting to note that among the four molecules, only thin-films of $\mathbf{2}$ are subjected to a significant structural reorganization with time or thermal treatment leading to an impressive reduction of the bandgap down to $1.72 \mathrm{eV} \cdot{ }^{[32]}$ Thus, contrary to 2 , the structure and hence the optical properties of thin-films of Tetra-2 do not change with time or thermal annealing, probably due to its 3D structure preventing any reorganization in the solid state. 

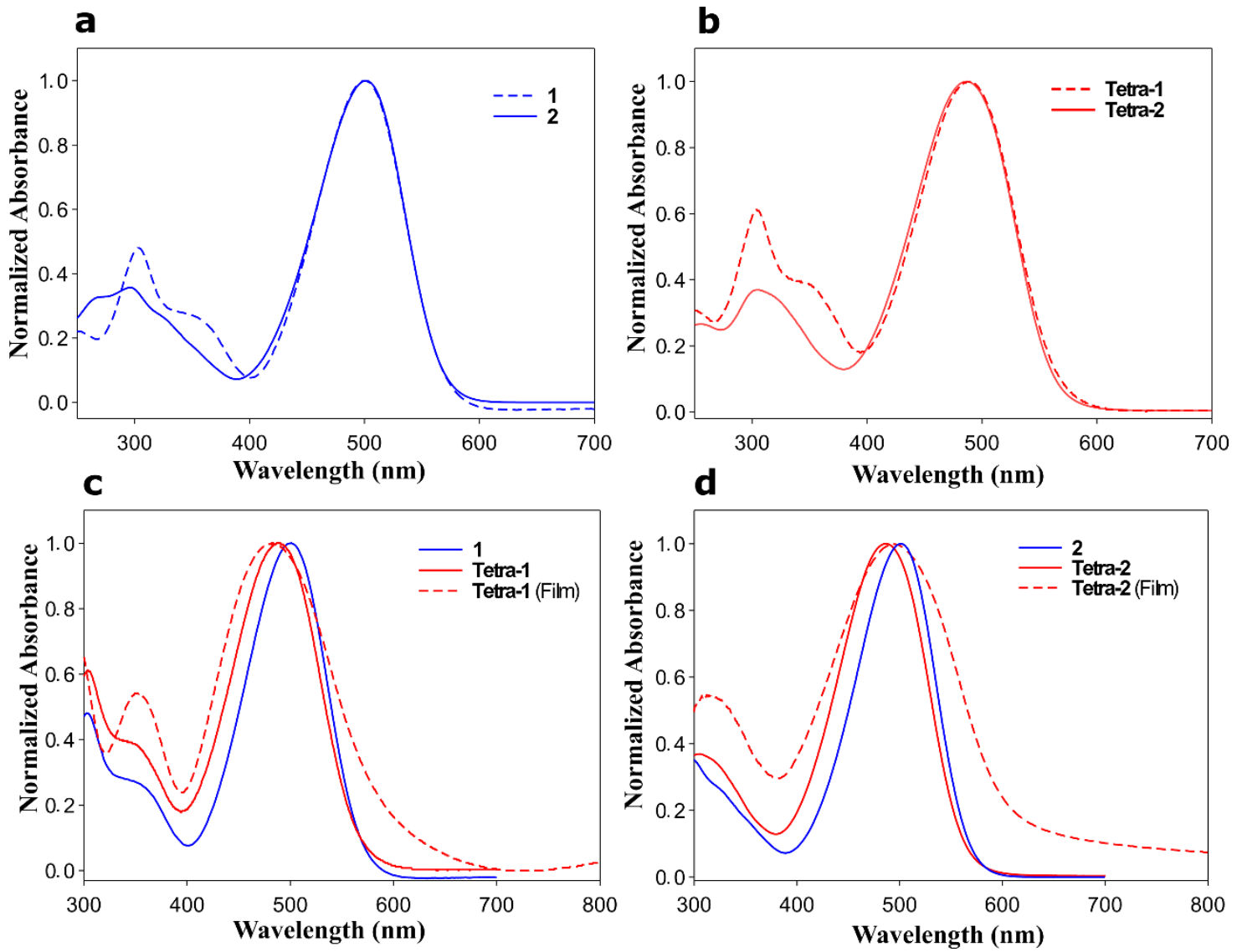

Figure 1. Normalized UV-vis spectra of molecules (a) 1, 2 and (b) Tetra-1, Tetra-2 (ca. $10^{-5} \mathrm{M}$ ) in $\mathrm{CH}_{2} \mathrm{Cl}_{2}$. Comparison with UV-vis spectra of thin-films of (c) Tetra-1 and (d) Tetra-2 on glass.

Electrochemical and spectroelectrochemical characterizations. Tetra-2 was shown to present a relatively low solubility in common organic solvents thus limiting its exploitation in OPV. On the other hand, it presents an interesting behavior upon electrochemical oxidation. Thus the electrochemical properties of Tetra-2 have been analyzed by cyclic voltammetry and the optical signature of the related oxidized species has been characterized by spectroelectrochemistry. In order to better understand the specific electrochemical behavior of Tetra-1 and Tetra-2, the reference push-pull compounds $\mathbf{1}$ and $\mathbf{2}$ were first studied and compared. Both molecules are characterized by the same molecular architecture, consisting of a small push-pull system based on an arylamine donor block, triphenylamine (TPA) or methyldiphenylamine (MeDPA) respectively, and a dicyanovinyl acceptor. The donor (D) and acceptor (A) moieties are connected together by a thienyl $\pi$ linker. In previous works the substitution of one of the outermost phenyl groups of TPA with a methyl group was shown to lead to a weak impact on the optical properties of the chromophores in solution. A major effect was instead observed at the level of crystalline structure, where a more compact packing is observed for the methyl substituted molecule, resulting in improved transport properties. ${ }^{[32]}$ The latter results from a co-facial arrangement of push-pull molecules $\mathbf{2}$ in the solid state, whereas a head to tail organization is observed for the phenyl substituted one. ${ }^{[13,17]}$ 
As described in this work, the substitution of an outer phenyl with a methyl group has a strong impact on the stability of the oxidised states of the molecules. Figure 2 shows the oxidative cyclic voltammogram (CV) pattern of chromophores 1 (a) and 2 (b) in $0.1 \mathrm{M} \mathrm{n}-\mathrm{Bu}_{4} \mathrm{NPF}_{6} / \mathrm{CH}_{2} \mathrm{Cl}_{2}$. The $\mathrm{CV}$ of chromophore 1 is characterized by a single reversible oxidation peak with a half wave potential of $0.51 \mathrm{~V} v s \mathrm{Fc} \mid \mathrm{Fc}^{+}$, which can be associated to the one electron oxidation of TPA donor to its radical cation state. ${ }^{[13-15,32]}$

On the other hand, the CV pattern of chromophore 2 upon oxidation is characterized by a chemically irreversible peak at $0.64 \mathrm{~V} v s \mathrm{Fc} / \mathrm{Fc}^{+}$in the first cycle in the forward scan and two reversible peaks at half wave potentials of $0.33 \mathrm{~V}$ and $0.52 \mathrm{~V}$ vs $\mathrm{Fc} / \mathrm{Fc}^{+}$, respectively, observed for the backward scan and subsequent oxidation cycles, Figure $2 \mathrm{~b}$. We explain the $\mathrm{CV}$ with the formation of reactive radical cations undergoing a follow up process which can be attributed to the dimerization at the para position of the phenyl ring, creating covalent biphenyl bonds. The so formed dimethyl-diphenyl-benzidine can then be reversibly oxidized to its radical cation and dication state in two distinct oxidation steps ${ }^{[32]}$ This mechanism is very probable since the behavior of chromophore $\mathbf{2}$ is almost identical to the CV of TPA moieties which can be oxidized to tetraphenylbenzidine moieties as shown earlier in literature. ${ }^{[13-15]}$ Due to the overimposition of the irreversible oxidation peak of chromophore 2 and of the benzidine dication, voltammetric measurements performed in thin-layer conditions (Figure 4a, Figure 4b) allow a better differentiation of the oxidation events discussed above. Evidence of the dimerization process can also be found in the spectroelectrochemical characterization of compound $\mathbf{2}$ where different absorption patterns are observed for the first and second oxidation cycles, indicating the formation of new chemical species. Further, theoretical calculations are employed to explain the observed reactivity behavior of compounds $\mathbf{1}$ and $\mathbf{2}$, which is presented in Scheme 3. 

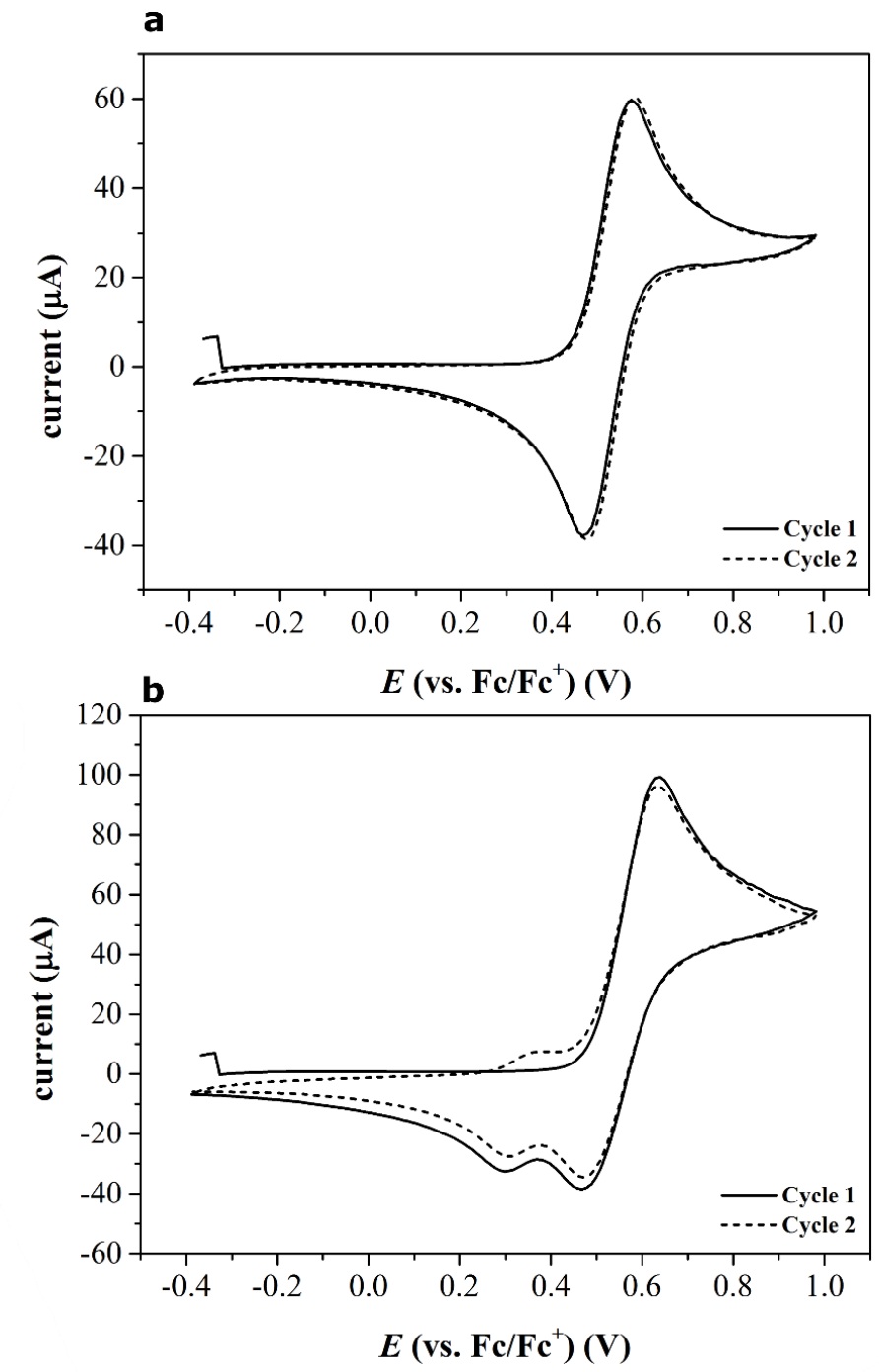

Figure 2. First and second cycle $\mathrm{CV}$ traces for push-pull molecules 1 (a) and 2 (b): $0.5 \mathrm{mM}$ in $0.1 \mathrm{M}$ n$\mathrm{Bu}_{4} \mathrm{NPF}_{6} / \mathrm{CH}_{2} \mathrm{Cl}_{2}$, Au working electrode, scan rate $50 \mathrm{mV} \cdot \mathrm{s}^{-1}$. 
$\mathbf{a}$<smiles>N#CC(C#N)=Cc1ccc(-c2ccc([N+](c3ccccc3)(c3ccccc3)c3ccc(-c4ccc(C=C(C#N)C#N)s4)cc3)cc2)s1</smiles>

$\mathbf{b}$<smiles>[X]c1ccc(N(C)c2ccc(-c3ccc(C=C(C#N)C#N)s3)cc2)cc1</smiles><smiles>Cc1ccc(C=C(C#N)C#N)s1</smiles><smiles></smiles><smiles>Cc1ccccc1</smiles><smiles>C=[N+](c1ccc(-c2ccc(C=[N+](C)c3ccc(C=C(C#N)C#N)s3)cc2)cc1)c1ccc(-c2ccc(C=C(C#N)C#N)s2)cc1</smiles><smiles></smiles>

Scheme 3. Sketch highlighting the most probable mechanism for the oxidation and follow-up reactions for push-pull molecules (a) 1 and (b) 2. ${ }^{[13-15]}$

In-situ spectroelectrochemical experiments were performed with the aim of studying the absorption profiles of chromophore molecules as a function of the oxidation potential in order to correlate the shape of the CV 
waves with the nature of the species involved in the oxidation process. To follow the variation of the relative abundances of the chemical species involved in the electrochemical oxidation, the progression of the absorbance as function of the potential is monitored $_{-5}$ Further, this results particularly useful in allowing an insight into irreversible chemical dimerization processes of the two chromophores.
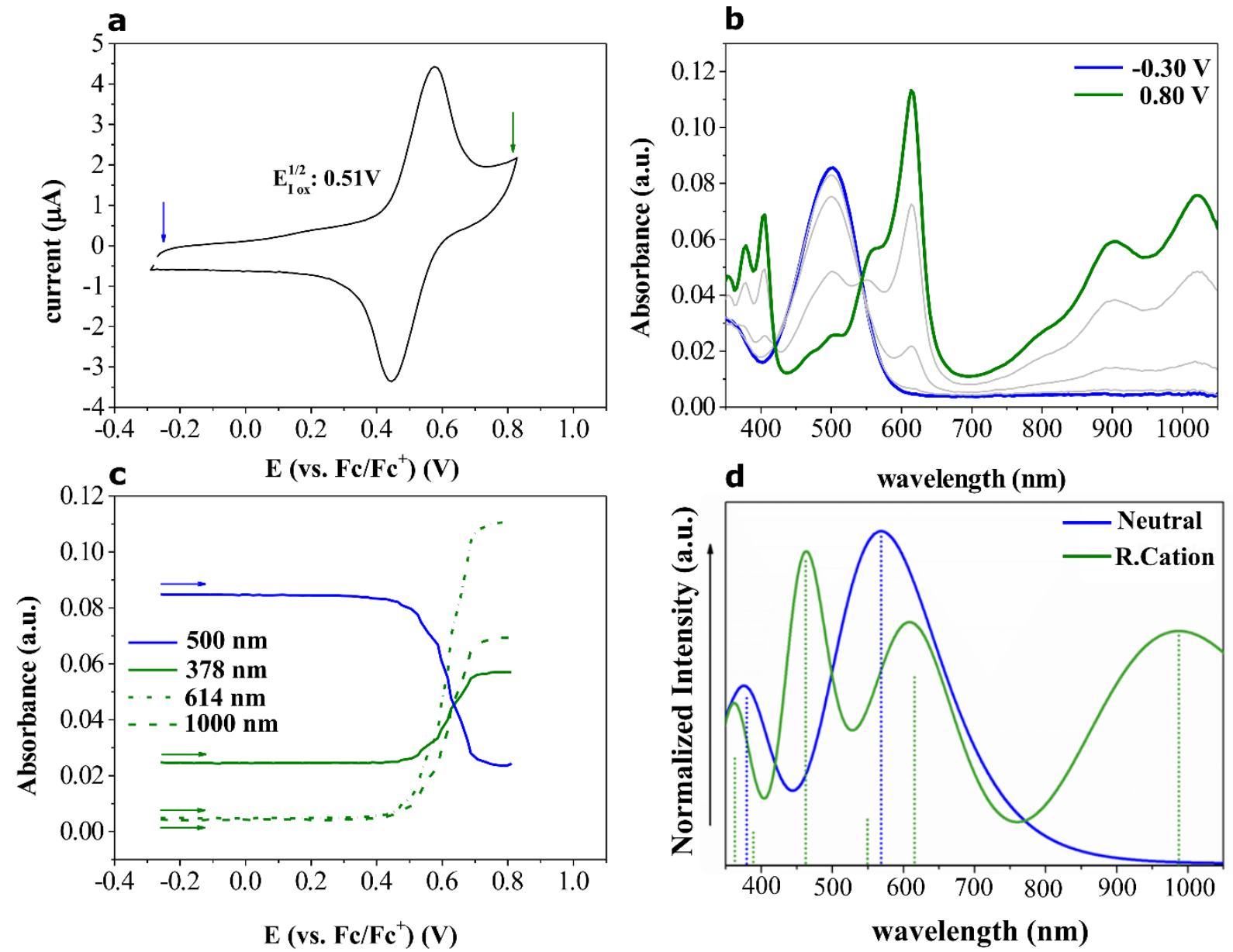

Figure 3. In-situ thin layer spectroelectrochemistry of chromophore 1: (a) CV pattern for the first oxidation cycle in $0.1 \mathrm{M} \mathrm{n}-\mathrm{Bu}_{4} \mathrm{NPF}_{6} / \mathrm{CH}_{2} \mathrm{Cl}_{2}, 20 \mathrm{mV} \cdot \mathrm{s}^{-1}$ in a $0.2 \mathrm{mM}$ solution of the chromophore; (b) UV-Vis spectra and (c) evolution of four characteristic absorption bands recorded during the forward scan of the spectroelectrochemical experiment in a). (d) Simulated absorption spectra and main excitations (oscillator strength vs. wavelength) shown as vertical bars for neutral (blue line) and radical cation (green line) of compound $\mathbf{1}$ as determined with TD-DFT at the B3LYP/6$31 \mathrm{G}^{* *}$ level in $\mathrm{CH}_{2} \mathrm{Cl}_{2}$.

In-situ spectroelectrochemistry of chromophore $\mathbf{1}$ is shown in Figure 3. When the WE is polarized at -0.30 $\mathrm{V} v s \mathrm{Fc} \mid \mathrm{Fc}^{+}$, the solution of neutral 1 shows one main absorption band at $500 \mathrm{~nm}$ (Figure 3b, blue line). The progressive molecule oxidation until $+0.80 \mathrm{~V} v s \mathrm{Fc} \mid \mathrm{Fc}^{+}$leads to the bleaching of this band with concomitant formation of new bands around 378, 614 and $1000 \mathrm{~nm}$, endowed with a pronounced vibronic structure. Two isosbestic points at 420 and $540 \mathrm{~nm}$ indicate that two species are in equilibrium in solution which is consistent with the gradual conversion of the neutral species into the radical cation. ${ }^{[3]}$ 
The presence of only one species resulting from the oxidation of compound $\mathbf{1}$ is also clear by analysing the absorption variation as a function of the potential (Figure 3c) at the main $\lambda_{\max }: 500 \mathrm{~nm}$ (neutral 1) and 378; 614; $1000 \mathrm{~nm}$ (radical cation 1).The absorption variations during the forward oxidation scan start concomitantly at $0.45 \mathrm{~V}$, which is the onset of molecule $\mathbf{1}$ oxidation (absorption decrease for the neutral and increase for the radical cation of chromophore 1 respectively) with a monotone variation. No transient absorption band (increasing and subsequently decreasing) developing at potential values subsequent to the oxidation onset is observed. No evidence for the formation of other species was therefore found. Further, the experimental evolution of the absorption spectra of compound $\mathbf{1}$ upon oxidation is well captured by the calculated electronic transitions when going from neutral and radical cation state, supporting the assignment of the charged states (Figure 3d). For instance, time-dependent density functional theory (TD-DFT) calculations predict a strong absorption band at $569 \mathrm{~nm}$ for the neutral state and three main electronic transitions calculated at 462,616, and $987 \mathrm{~nm}$ for the radical cation state (see supporting information for a description of the nature of these electronic transitions).

Before analyzing the spectroelectrochemical behavior of chromophore 2, it is important to remind that potentiodynamic measurements in thin layer conditions are associated with a complete conversion of all the starting species and to their regeneration only in the case of a chemically-reversible process. In these conditions not just the irreversible oxidation process can be pictured through different absorption patterns, from the first forward oxidation scan to the subsequent scans, but we can also observe clearly from the CV pattern two discrete oxidation peaks which are attributed to the dimethyl-diphenyl-benzidine radical cation and dication respectively; without the superposition of the monomer oxidation peak. 

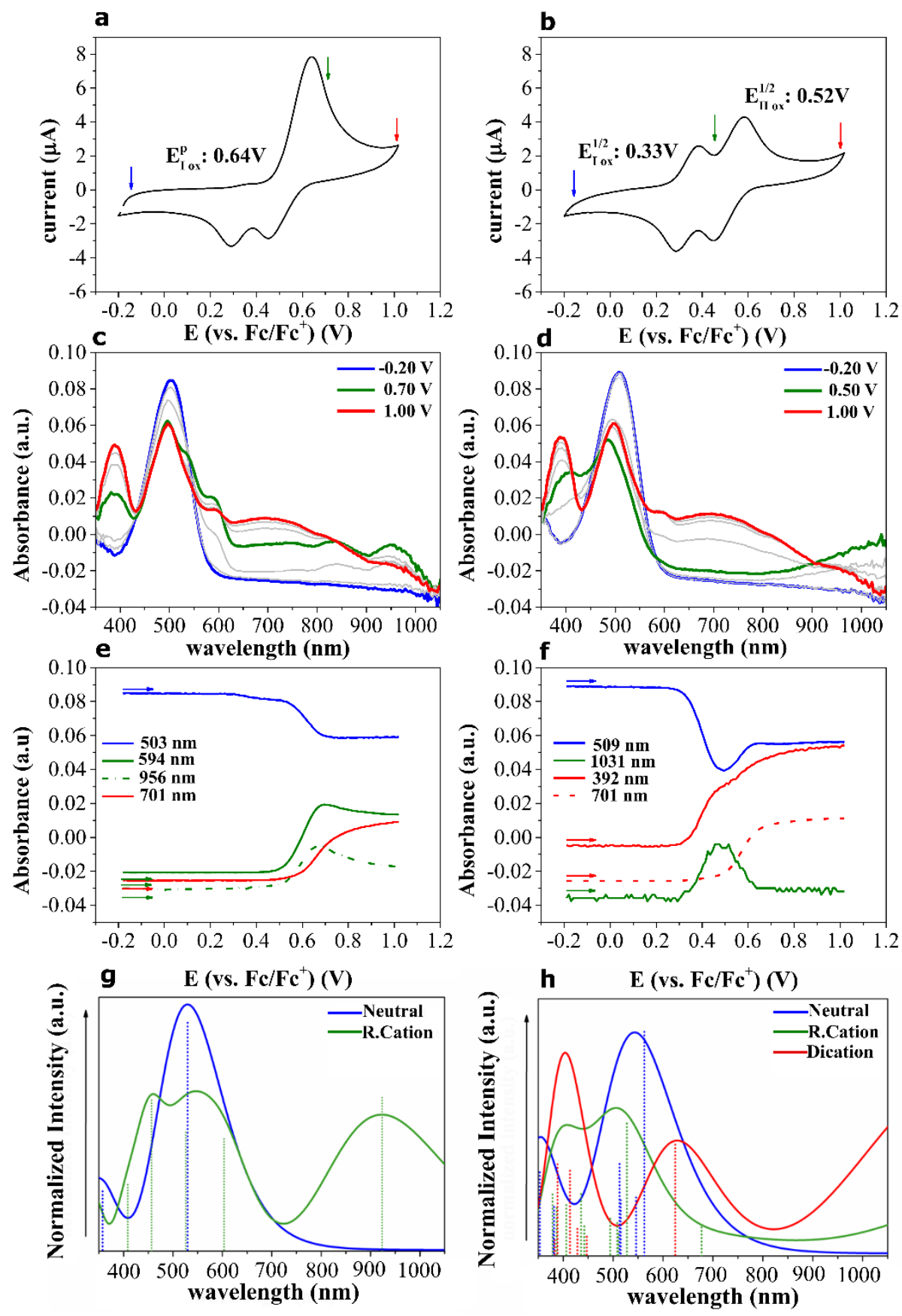

Figure 4. In-situ thin layer spectroelectrochemistry of chromophore 2: (a) CV pattern for the first oxidative cycle of push-pull molecule 2 (monomer) $0.2 \mathrm{mM}$ in $0.1 \mathrm{M} \mathrm{n}-\mathrm{Bu}_{4} \mathrm{NPF}_{6} / \mathrm{CH}_{2} \mathrm{Cl}_{2}, 20 \mathrm{mV} \cdot \mathrm{s}^{-1}$; (b) $\mathrm{CV}$ second cycle corresponding to the oxidation of chromophore 2 (dimer). (c) UV-Vis spectra recorded during the first forward scan of the spectroelectrochemical experiment (monomer) in a); (d) UV-Vis spectra recorded during the second forward scan (dimer) in b); (e, f) evolution of four characteristic absorption bands during the first and second forward oxidation scans in a) and b) respectively; (g; h) Simulated absorption spectra and main excitations (oscillator strength vs. wavelength) shown as vertical bars for neutral (blue lines), radical cation (green lines) and dication (red lines) of pushpull molecule 2 (monomer) (g) and its dimer (h) respectively, as determined with TD-DFT at the B3LYP/6-31G** level in $\mathrm{CH}_{2} \mathrm{Cl}_{2}$. 
Figure $4 \mathrm{c}$ pictures the potential dependent absorption spectra of chromophore $\mathbf{2}$ in solution. The blue curve recorded at $-0.20 \mathrm{~V} v s \mathrm{Fc}^{+} \mid \mathrm{Fc}$ corresponds to the absorption pattern of the neutral chromophore in solution. Two bands are observed, one at wavelengths below $350 \mathrm{~nm}$ (Figure S5 in the supporting information) and one with a maximum at $503 \mathrm{~nm}$. The former one can be assigned to a $\pi$ - $\pi^{*}$ electronic transition whereas the latter is due to an internal charge transfer (ICT). ${ }^{[28,34]}$ This is in good accordance with DFT calculations that predict that the low energy band is associated with a HOMO $\rightarrow$ LUMO one-electron excitation which implies an electron density transfer from the thienyl spacer including the electron donor group to the electron-withdrawing group (Figure S11 and S18 in the supporting information). The potential-dependent absorption for the first forward oxidation scan of compound 2 (Figure 4c) differs from the one observed in subsequent polarization cycles (Figure 4d; Figure S5 in the supporting information). This experimental result is consistent with the formation of new species upon electrochemical oxidation of compound 2 leading to dimers. ${ }^{[14,29,32]}$ The progressive increase of the WE oxidation potential induces a bleaching of the two absorption bands of $\mathbf{2}$ in its neutral form and the development of different maxima at 392, 550, 594, 840 and $956 \mathrm{~nm}$ (Figure $4 \mathrm{c}$, green curve at $+0.70 \mathrm{~V} v s \mathrm{Fc} \mid \mathrm{Fc}^{+}$). For higher polarization potentials, two main maxima of absorption are observed at 392 and $498 \mathrm{~nm}$ (bands that are also involved in the radical cation state) together with a new broad band centered at $701 \mathrm{~nm}$ (Figure $4 \mathrm{c}$, red curve at $+1.00 \mathrm{~V} v s \mathrm{Fc} \mid \mathrm{Fc}^{+}$) which can be ascribed to the dication state of the dimeric form of the chromophore. ${ }^{[20]}$ This statement is confirmed by the same optical signature observed for the dimers of chromophore 2 recorded at $+1.00 \mathrm{~V} v s \mathrm{Fc} / \mathrm{Fc}^{+}$(Figure $4 \mathrm{c}$, red curve). When comparing the absorption maxima for the neutral dimer with respect to pristine compound 2, a slight red-shift from $503 \mathrm{~nm}$ (monomer) to $509 \mathrm{~nm}$ (dimer) is observed (line at $-0.20 \mathrm{~V} v \mathrm{~s}$ $\mathrm{Fc}^{+} \mid \mathrm{Fc}$ Figures 3c, 3d) in agreement with the slightly increased conjugation with the extension of the conjugated core. In addition, the examination of the in-situ absorption pattern for the following cycles for intermediate oxidation potentials (Figure $4 \mathrm{~d}$ : green line at $+0.50 \mathrm{~V} v s \mathrm{Fc}^{+} \mid \mathrm{Fc}$ ) shows a different behavior with a characteristic single broad band at wavelengths higher than $1050 \mathrm{~nm}$ and two maxima of absorption at 398 and $496 \mathrm{~nm}$; this absorption pattern is then maintained for the subsequent charge/discharge cycles.

The measured absorption spectra of chromophore $\mathbf{2}$ and its charged states as well as for its dimeric form can also be satisfactorily compared with the TD-DFT calculated vertical transition energies (Figure $4 \mathrm{~g}$ and Figure $4 \mathrm{~h}$ respectively). Also in this case, a red-shift in the absorption maxima of the neutral species upon dimerization is predicted from the B3LYP calculated values (530 nm for 2 vs $563 \mathrm{~nm}$ for its dimer) Particularly significant in supporting the band assignment is the change in the calculated absorption pattern of the radical cation for pristine 2 (Figure $4 \mathrm{~g}$ ) and that of its dimer (Figure $4 \mathrm{~h}$ ). While for the radical cation of monomer 2 theory predicts a broad band between 400-600 $\mathrm{nm}$ due to different electronic transitions and an intense absorption band at $923 \mathrm{~nm}$, a different behavior is found for the radical cation of its dimer with a very intense electronic transition predicted at $527 \mathrm{~nm}$ and another one with low intensity at $934 \mathrm{~nm}$ in 
agreement with experimental data (for a description of the electronic nature of these transitions, see the supporting information). Note that this trend is even better captured by the M06-2X functional, which includes mid-range interactions, and a more pronounced red-shifting of the lowest energy transition is predicted when going from the radical cation state of chromophore 2 to that of its dimer, calculated at 774 $\mathrm{nm}$ and $1040 \mathrm{~nm}$, respectively (Figure S5 in the supporting information).

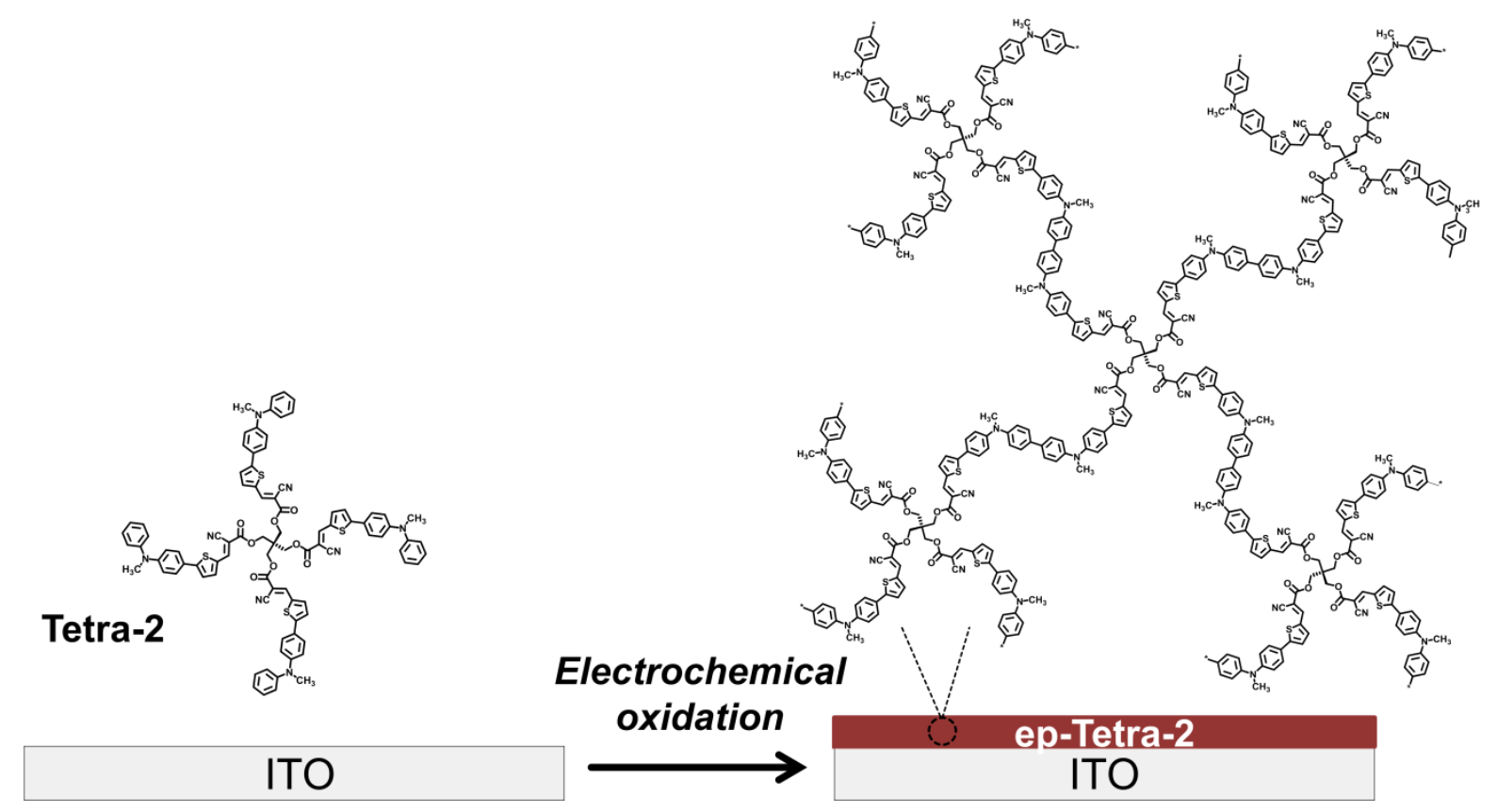

Figure 5. Schematic representation of the oxidative electropolymerization of Tetra-2 to ep-Tetra-2 on ITO.

Tetra-2 electropolymerization, Figure 5. The oxidative voltammetric pattern and subsequent potentiodynamic cycles recorded during the electrodeposition of Tetra-2 on ITO are presented in Figure 6a. The CV pattern for the monomer oxidation consists of a single irreversible oxidation peak at $0.51 \mathrm{~V} v \mathrm{~s}$ $\mathrm{Fc} \mid \mathrm{Fc}^{+}$. This peak can be assigned to the oxidation of the four independent push-pull units linked to the nonconjugated central pentaerythritol $\sigma$-linker generating a tetra-radical cation species. The oxidative peak for the one-electron oxidation of Tetra-2 monomer falls at $0.51 \mathrm{~V}$ vs $\mathrm{Fc} \mid \mathrm{Fc}^{+}$, slightly shifted towards less positive oxidation potential with respect to the first oxidation of chromophore $2(0.64 \mathrm{~V})$ (Figure $4 \mathrm{a})$. Tetra$\mathbf{2}$, in analogy with what was observed for chromophore $\mathbf{2}$, readily undergoes an oxidative electropolymerization process involving the coupling of the arylamine radical cation at the free phenyl para position, with formation of biphenyl bonds. From the $\mathrm{CV}$ pattern recorded during electropolymerization a steady and regular film growth within consecutive cycles can be observed. The progressive deposition of electroactive material on the electrode surface is indeed associated with increasing current registered for each subsequent cycle. Due to the branched nature of the starting monomer we expect a highly crosslinked material, generated upon dimerization into dimethyl-diphenyl-benzidine units. The latter, modulated by the 
interactions between neighbouring units on the electrode surface, dominate the redox behaviour of electrodeposited Tetra-2 film.

The oxidative voltammetric pattern of ep-Tetra-2 in a monomer free electrolyte show a stable behaviour upon subsequent cycling in the potential region -0.4 and $0.8 \mathrm{~V}$ vs $\mathrm{Fc}_{\mathrm{Fc}} \mathrm{Fc}^{+}$(See Figure $\mathrm{S} 8$ in the Supporting Information), exhibiting a broad oxidation wave peaking at $0.36 \mathrm{~V}$ with a shoulder at $0.44 \mathrm{~V}$ (Figure $6 \mathrm{~b}$ ).

The onset of oxidation of ep-Tetra-2 estimated at $0.2 \mathrm{~V} v s \mathrm{Fc} / \mathrm{Fc}^{+}$corresponds to a HOMO level at $-5.3 \mathrm{eV}$ while the optical bandgap calculated from the ICT band onset $\left(\lambda_{\text {onset }}=625 \mathrm{~nm}\right)$ for ep-Tetra-2 film is estimated at $1.98 \mathrm{eV}$. The potentiodynamic deposition of Tetra-2 was also performed on a Pt working electrode, showing a similar voltammetric pattern (see Figure S8 in the Supporting Information).

Analogously as for chromophore 1, the electrochemical oxidation of Tetra-1 in $0.1 \mathrm{M} \mathrm{n}-\mathrm{Bu}_{4} \mathrm{NPF}_{6} / \mathrm{CH}_{2} \mathrm{Cl}_{2}$ is characterized with a single chemically reversible oxidation peak, assigned to the concomitant oxidation of the four independent push-pull units to the radical cation state, without involving irreversible follow-up reactions (see Figure S10 in the Supporting Information). ${ }^{[31]}$
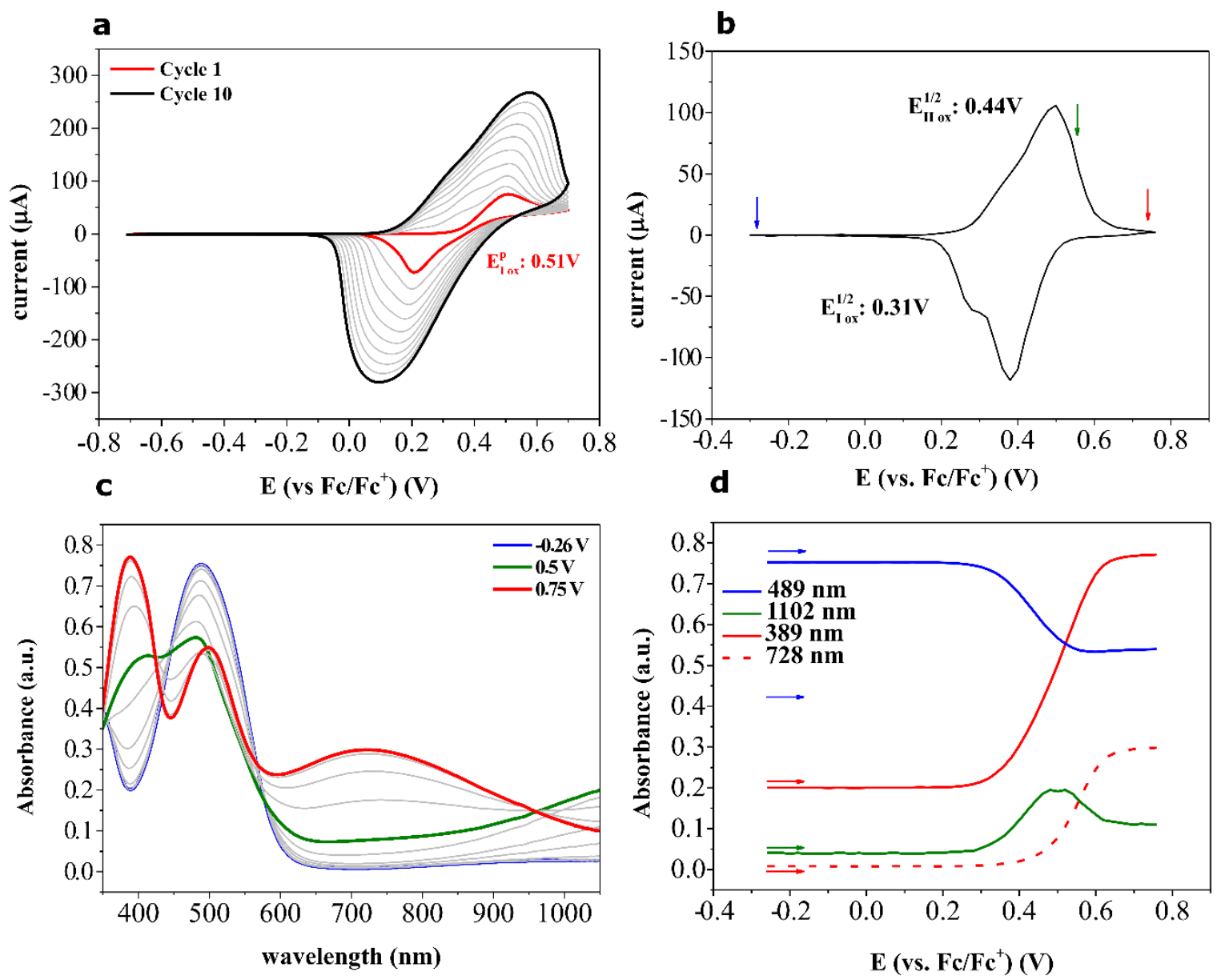
Figure 6. Tetra-2: (a) CV pattern for the potentiodynamic electrodeposition of Tetra-2 on ITO $0.5 \mathrm{mM}$ in $0.1 \mathrm{M}$ $\mathrm{TBAPF}_{6} / \mathrm{CH}_{2} \mathrm{Cl}_{2}, 10$ cycles, $50 \mathrm{mV} \cdot \mathrm{s}^{-1}$. (b) $\mathrm{CV}$ oxidation profile in $0.1 \mathrm{M} \mathrm{n}-\mathrm{Bu}_{4} \mathrm{NPF}_{6} / \mathrm{CH}_{2} \mathrm{Cl}_{2} ; 50 \mathrm{mV} \cdot \mathrm{s}^{-1}$ of electropolymerized ep-Tetra-2 film; (c) and (d) in-situ thin film spectroelectrochemistry of electropolymerized epTetra-2, with c) UV-Vis spectra and d) evolution of four characteristic absorption bands recorded during the forward scan of the spectroelectrochemical experiment in b).

Figure 6c shows the changes in the absorption spectra of an electropolymerized ep-Tetra-2 film recorded during UV-Vis in-situ spectroelectrochemical experiments for the forward oxidation scan. The UV-Vis absorption pattern of the electrodeposited tetramer in its neutral state $\left(-0.26 \mathrm{~V}\right.$ vs $\mathrm{Fc} \mid \mathrm{Fc}^{+}$, blue absorption spectrum) shows two maxima of absorption at wavelength below $350 \mathrm{~nm}$ and $489 \mathrm{~nm}$, respectively. The particularly intense band observed for the polymer film in its neutral state at $489 \mathrm{~nm}$ can be assigned to an ICT band, while the one at shorter wavelengths to a $\pi-\pi^{*}$ electronic transition. ${ }^{[28,34]}$ The anodic polarization for values of potential between -0.26 and $0.5 \mathrm{~V} v s \mathrm{Fc} \mid \mathrm{Fc}^{+}$leads to the formation of a new absorption band, with maxima at wavelengths higher than $1050 \mathrm{~nm}$ (See Figure S7 in the Supporting information) together with the development of two new bands at 392 and $482 \mathrm{~nm}$, respectively, and concomitant bleaching of the neutral bands at $\lambda_{\max }<350 \mathrm{~nm}$ and at $489 \mathrm{~nm}$. The broad band with absorption maxima at $1050 \mathrm{~nm}$ in the NIR region generated for polarization potentials for values in between 0.3 and $0.56 \mathrm{~V}$ should be reasonably attributed to the radical cation state of the polymer. The progressive conversion of the neutral species into its radical cation state also results in an isosbestic point around 580-600 nm. By further increasing the oxidation potential of the polymer film to $0.75 \mathrm{~V} v s \mathrm{Fc}^{+} \mid \mathrm{Fc}$ new absorption bands with maxima at 389, 500 and $728 \mathrm{~nm}$ are observed, with concomitant vanishing of the polaron band at >1050 nm. This new band generated at $728 \mathrm{~nm}$ should be reasonably attributed to the dication state of the polymer. ${ }^{[35,36]}$ Comparing the spectroelectrochemical behavior of the electropolymerized Tetra-2 with the one of the dimer of chromophore 2 (Figure $4 \mathrm{~d}$ ) strong similarities are observed in the variation of the absorption spectra upon oxidative polarization. These encountered similarities are consistent with the molecular structure and the similar electrochemical behavior observed upon oxidation. Table 2 summarizes the optical characteristics of electropolymerized- Tetra-2, and chromophores 1 and $\mathbf{2}$ upon electrochemical oxidation. Both the epTetra-2 and the dimer of chromophore 2 present a similar absorption pattern upon electrochemical oxidation. In particular, the absorption band at $\lambda_{\max }>1050 \mathrm{~nm}$ observed for the electropolymerized tetramer film and assigned to the radical cation state is also observed for the first oxidation peak, i.e oxidation to the radical cation of the dimer of chromophore 2. Analogously, both systems present for higher values of oxidation potential a band around $700 \mathrm{~nm}$, assigned to the dication state. These experimental observations are consistent with the fact that, independently from the number of monomer units constituting the electropolymerized tetramer film, the same dimethyl-diphenyl-benzidine redox unit is responsible for the electrochemical properties of the dimer of compound $\mathbf{2}$ and of ep-Tetra-2 (although partially modulated by the degree of planarity and possible reciprocal chain interaction in the electrodeposited film of the latter). 
Table 2. Optical absorption characteristics upon electrochemical oxidation of push-pull molecules 1, 2 (monomer and dimer) in thin layer conditions $\left(0.2 \mathrm{mM}\right.$ in $\left.0.1 \mathrm{M} \mathrm{n}-\mathrm{Bu}_{4} \mathrm{NPF}_{6} / \mathrm{CH}_{2} \mathrm{Cl}_{2}\right)$ and of ep-Tetra-2 film recorded in $0.1 \mathrm{M}$ $\mathrm{Bu}_{4} \mathrm{NPF}_{6} / \mathrm{CH}_{2} \mathrm{Cl}_{2}$. The values in brackets might be associated with the same species, radical cation of 2 that, despite thin-layer conditions, is generated do to partial diffusion of $\mathbf{2}$ from the bulk solution.

\section{Electrochemical potential}

$\lambda_{\max }(\mathbf{n m})$

$\left(\right.$ V vs. Fc/Fc $\left.{ }^{+}\right)$

\begin{tabular}{|c|c|c|c|c|c|c|}
\hline Species & Neutral & $\begin{array}{l}\text { Radical } \\
\text { cation }\end{array}$ & Dication & $E_{I, o x}^{\mathrm{P}}$ & $E_{I, o x}^{1 / 2}$ & $E_{I I, o x}^{1 / 2}$ \\
\hline 1 & $<350 ; 500$ & $\begin{array}{c}378 ; 614 ; \\
1000\end{array}$ & - & - & 0.51 & - \\
\hline 2-monomer & $<350 ; 503$ & $\begin{array}{c}\text { 550; (594); } \\
840 ; 956\end{array}$ & - & 0.64 & - & - \\
\hline 2-dimer & $<350 ; 509$ & $\begin{array}{c}398 ; 496 \\
>1050\end{array}$ & $\begin{array}{l}\text { 392; 498; } \\
(593) ; 701\end{array}$ & - & 0.33 & 0.52 \\
\hline Tetra-2 & $486 \mathrm{~nm}$ & - & - & 0.51 & - & - \\
\hline ep-Tetra-2 & $<350 ; 489$ & $\begin{array}{c}392 ; 482 \\
>1050\end{array}$ & 389,$500 ; 728$ & - & 0.31 & 0.44 \\
\hline
\end{tabular}

\section{Discussion}

DFT calculations of compounds $\mathbf{1}$ and $\mathbf{2}$ were performed in order to provide an explanation of the different reactivity observed for the two chromophores upon electrochemical oxidation. In literature several works can be found describing the electrochemical behaviour of aromatic amines upon oxidation. ${ }^{[13-15,37]}$

The oxidative pathway of tri-substituted aromatic amines is described as an EC mechanism (namely electrochemical-chemical mechanism), resulting in the dimerization at the para position of the phenyl ring. 
The reaction pathway includes the radical formation upon electrochemical oxidation followed by the coupling of the radicals followed by deprotonation. When analysing the reactivity towards dimerization of different classes of tri-substituted aromatic amines, the spin density at the phenyl para-position and the blocking of the latter are two determining factors defining the reactivity of the amine radical cations. ${ }^{[15,38-}$ ${ }^{40]}$ It is important to consider that, by analogy with redox active $\pi$-conjugated systems, the nature of substituents at the arylamine para-position can influence the radical stability towards the coupling reaction both from a thermodynamic and a kinetic point of view. Radical cations can indeed be thermodynamically stabilized by an increase or more efficient conjugation of the system as well as by introducing electrondonor groups. ${ }^{[41]}$ Sterically hindered substituents or the blocking of the reactive sites (end-capping) can also diminish the reactivity of the radical-cation state towards the coupling reaction. ${ }^{[14,42-44]}$ For instance, Bäuerle et al. reported the electrochemical behaviour upon oxidation of a series of end capped oligothiophenes leading to the formation of stable radical cations when compared to highly reactive thiophenes. ${ }^{[45]}$ In this context, the study of Roncali et al. on the influence of steric effects on the electropolymerization of 3-alkyl thiophenes is also particularly interesting. ${ }^{[44]}$ The authors analyzed a different set of both linear and branched 3-alkyl substituted thiophenes in relation to their electropolymerization ability. They observed that, in the case of linear alkyl substituents, the length of the alkyl chain, besides influencing the structure and properties of the electrogenerated polymer, did not have a limiting effect on the monomer electropolymerizability. On the other hand, the presence of branched alkyl substituents completely hindered the electropolymerization. In this work, the attachment of the thienyl linker and dicyanovinyl acceptor-substituent to one phenyl ring of the aryl-amine leads to a delocalization of the charge over the whole $\pi$-conjugated system. Further, through their steric effect, substituents can play a significant role in the kinetic stabilization of the radical cation. Because of the substitution of the arylamine by the bulky $\pi$-extended system this last point might result particularly critical in our case. 


\section{a}
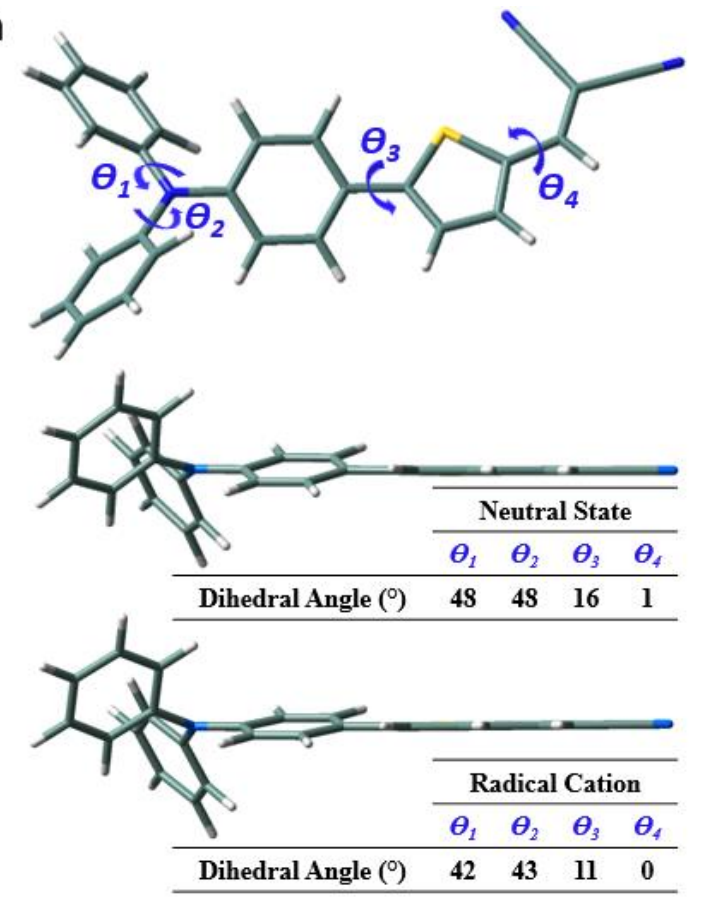

b
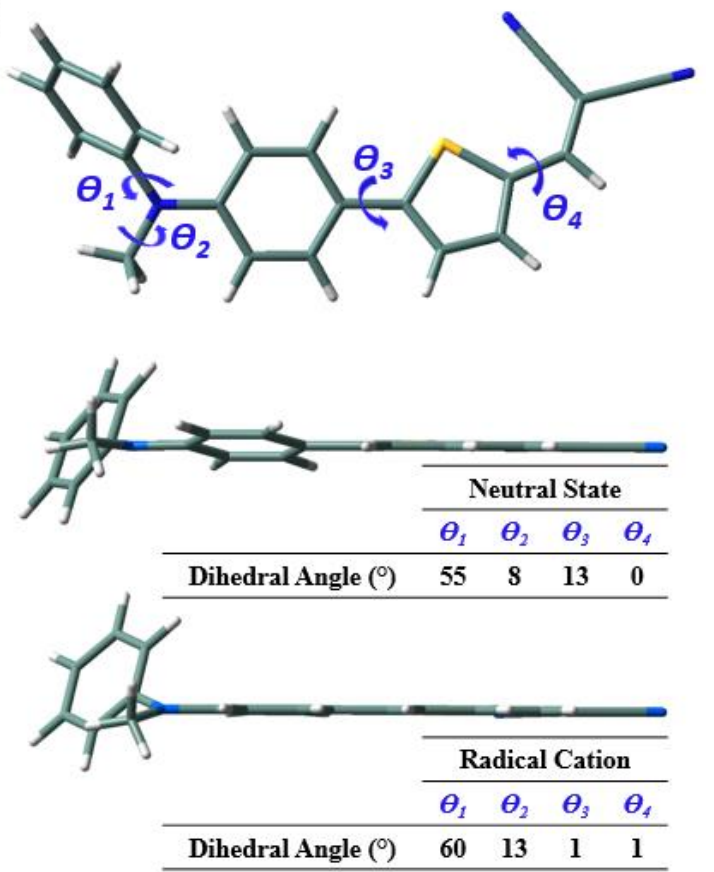

Figure 7. DFT-calculated dihedral angle values (B3LYP/6-31G** level in $\left.\mathbf{C H}_{2} \mathbf{C l}_{2}\right)$ and lateral views of the optimized geometries of the neutral and radical cation sates of compound $\mathbf{1}$ (a) and $\mathbf{2}$ (b).

The optimized molecular geometries of compounds $\mathbf{1}$ and $\mathbf{2}$ in their neutral state lead to a similar conformation with very close dihedral angle values between the adjacent thiophene and phenyl rings $\left(\theta_{3}=\right.$ $16^{\circ}$ for $1 v s 13^{\circ}$ for 2 ) (Figure 7). When oxidized to their radical cation state, $\mathbf{2}$ becomes more planar with respect to molecule 1 owing to a significant decrease of the aforementioned dihedral angle down to $1^{\circ}$ (Figure 7: see variation of dihedral angle number $3, \theta_{3}$ ). This higher degree of planarization for the radical cation is translated in a better delocalization of the positive charge over the whole $\pi$-conjugated system, with a large charge over the thienyl spacer group (i.e., $+0.299 e$ in compound $\mathbf{1} v s+0.341 e$ in compound $\mathbf{2}$, Figure $8 \mathrm{a}$ and Figure $8 \mathrm{~b}$ ). On the other hand, the spin density distribution in compound $\mathbf{2}$ is more delocalized over the whole $\pi$-conjugated system. The spin density distribution over the thienyl spacer and the dicyanovinyl group in compound $\mathbf{2}$ is larger when compared to compound 1, Figure 8c and Figure 8d. Interestingly, similar trends are found when comparing NPA and Mülliken spin densities (See Figure S17 in the supporting information). Consequently, contrary to what was initially expected to explain the oxidative dimerization process of compound $\mathbf{2}$, the spin density distribution on the peripheral $\mathrm{C}$ atom of the external phenyl group is slightly larger in chromophore $\mathbf{1}$ when compared to system $\mathbf{2}(+0.11 v s+0.06$, respectively). 

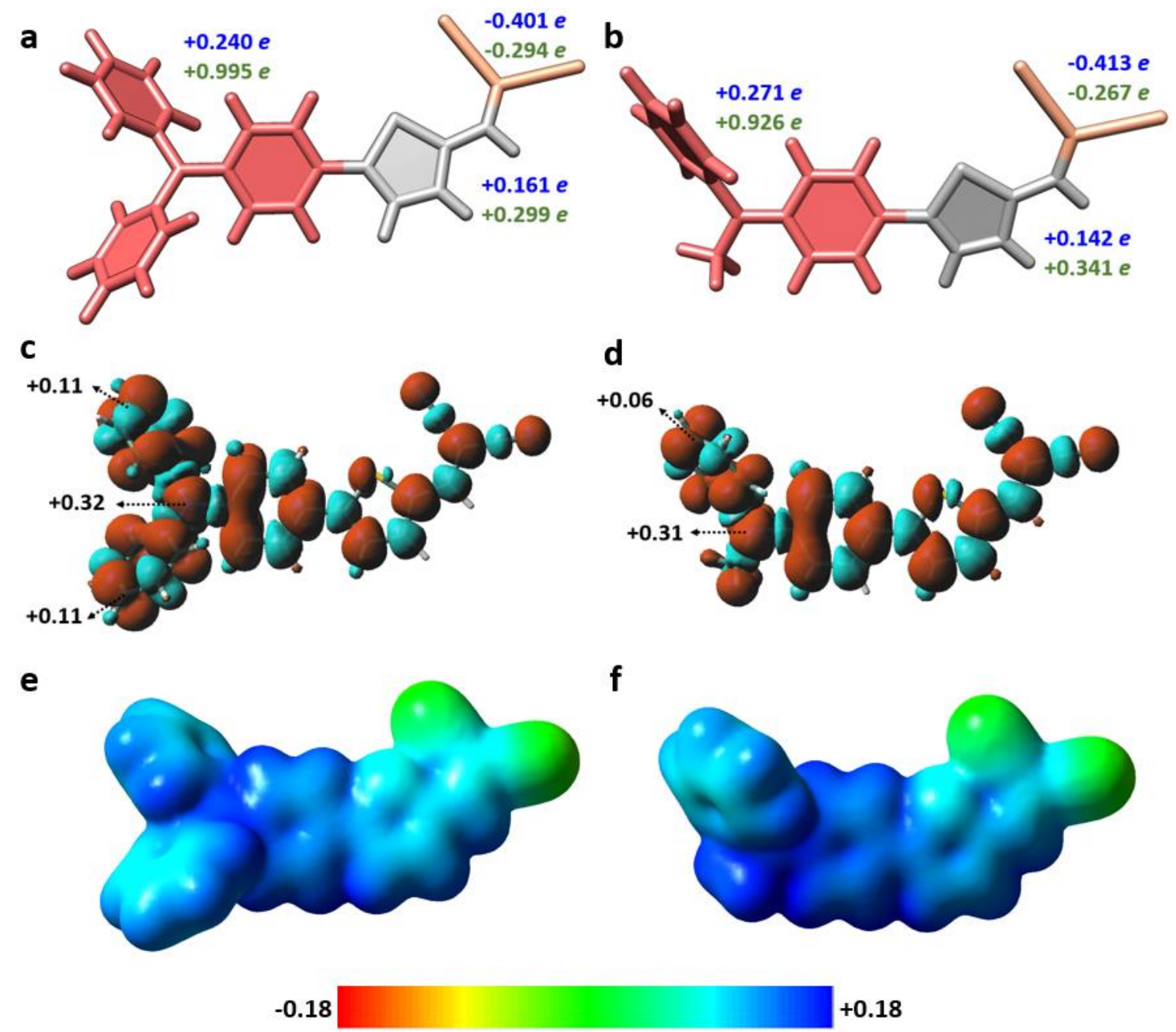

Figure 8. DFT-calculated Mülliken atomic charges (B3LYP/6-31G** level in $\mathbf{C H}_{2} \mathbf{C l}_{2}$ ) on various molecular domains for the neutral (blue) and radical cation (green) states of compounds (a) $\mathbf{1}$ and (b) $\mathbf{2}$. Mülliken spin density distribution in the radical cation state of push-pull molecules (c) $\mathbf{1}$ and (d) $\mathbf{2}$ at the same level of theory. The Mülliken spin densities of the carbon atoms at the phenyl para position and over the nitrogen atoms of the arylamine donor groups are also shown. Molecular electrostatic surface potential (ESP) for the radical cations of compounds e) $\mathbf{1}$ and f) 2, calculated over the electron density with an isovalue contour of 0.003 a.u.

The electrostatic surface potential (ESP) calculated by mapping the electrostatic potential onto the total electron density surface of the radical cation of compounds $\mathbf{1}$ and $\mathbf{2}$ is presented in Figure 8 e and f. It constitutes a useful technique to better visualize and understand the molecular reactivity. In the ESP surface nucleophilic regions are graphically shown as blue color and expressed as electron deficiency in those regions, while the electrophilic regions, where the electron distribution is dominant, are shown as red color. By analyzing the ESP surface of the radical cation of compounds 1 and $\mathbf{2}$ (Figure $8 \mathrm{e}$ and $\mathrm{f}$ ) it can be observed that both chromophores display low electron density regions that are spread on both donor and $\pi$-spacer moieties, while slightly higher electron density regions are found around the acceptor group. 
However, when comparing the two systems, a higher nucleophilic behavior over the donor moiety is found in compound $\mathbf{2}$ with respect to compound 1. This substantial redistribution of positive charge in $\mathbf{2}$ together with its more planar backbone could explain the easier coupling of two radical cation monomers when compared to compound $\mathbf{1}$, resulting in a favorable dimerization coupling.

As already stressed above, in literature, the coupling behaviour of arylamine radical cations is mostly explained in terms of high spin density values at the phenyl para position, and, more in general, the spin density distribution of radical cations can indeed serve as a useful reactivity parameter. ${ }^{[46][47]}$ In our case, the experimental results, showing a coupling of the radical cations of compound $\mathbf{2}$ whereas the radical cation of compound $\mathbf{1}$ are inert towards coupling, are not properly reproduced by the calculated spin density values. By contrast, our theoretical data point out that steric hindrance and electrostatic interactions seem to be important factors determining the favoured coupling behaviour in radical cations of compound $\mathbf{2}$ when compared to homologues of $\mathbf{1}$. It is also important to mention that the use of a functional parametrized for midrange interactions, M06-2X, was also tested. The same trends in spin density, molecular electrostatic potential distribution and backbone planarization of the radical cation and dication as those predicted at the B3LYP level were found (See figures S18 to S25 in the Supporting Information). Finally, geometry optimizations of the dication state of dimers of $\mathbf{1}$ and $\mathbf{2}$ were also performed (See Figures S26 to S31 in the supporting information). The more planarized conjugated backbones, more stabilized HOMO levels and more electron deficient central biphenyl rings support the higher stability of dication of dimer $\mathbf{2}$ when compared to that of dimer $\mathbf{1}$ and could be another explanation for the different coupling behavior of the two chromophores.

\section{Conclusions}

In conclusion, the synthesis of Tetra-2, a tetra-functionalized pentaerythritol core bearing diphenylmethylamine-based push-pull chromophores was described. The coupling reactivity of its radical cation was successfully exploited to generate a 3D push-pull network upon oxidative electropolymerization. The electrochemical behavior of the latter was analyzed and compared with the one of its linear push-pull chromophores $\mathbf{1}$ and $\mathbf{2}$, used as model compounds. Thin layer in-situ spectroelectrochemistry of compound 2 allowed the characterization of the different chemical species generated by the oxidation of the latter and identified with its dimers. A similar absorption trend was also found during the electrochemical oxidation of electropolymerized Tetra-2. These experimental observations are consistent with the fact that, independently from the number of monomer units constituting the electropolymerized tetramer film, the same dimethyl-diphenyl-benzidine redox unit is responsible for the electrochemical properties of both the dimer of compound $\mathbf{2}$ and electropolymerized-Tetra-2. No intermediate species were identified for the electrochemical oxidation of compound 1. Further, the measured potential dependent absorption spectra of 
push-pull molecules 1, 2 and of the dimer of compound $\mathbf{2}$ were satisfactorily compared with the TD-DFT calculated vertical transition energies, confirming the electronic nature of the different charged states. DFT calculations of compounds $\mathbf{1}$ and $\mathbf{2}$ were performed in order to provide an explanation of their different reactivity behavior. It was found that in the case analyzed, the spin density distribution at the phenyl para position, generally used as reactivity parameter for explaining the coupling behavior of arylamines, did not clarify alone the experimental observations. Theoretical data lead us to the hypothesis that steric hindrance and electrostatic interactions (EPS surface) seem to be here two important factors determining the coupling reactivity in radical cations of compound $\mathbf{2}$ and of Tetra-2 when compared to the reactivity of compound $\mathbf{1}$ and Tetra-1. Based on the promising results already obtained for push-pull compounds $\mathbf{1}$ and $\mathbf{2}$, future work will be devoted to the analysis of Tetra-2 and ep-Tetra-2 OPV properties as well as to the chemical doping and conductivity analysis of Tetra-2 films.

\section{Experimental Section}

The synthetic procedure for Tetra-2 is described in the Supporting Information.

Electrochemical measurements were performed with an Autolab PGSTAT204 potentiostat (Metrohm) at room temperature and under Argon atmosphere. A three-electrode glass cell provided with a Pt plate as counter electrode (CE) and an AgCl-coated silver wire as pseudo reference electrode (RE) were employed. As working electrode (WE) (a) $1 \mathrm{~cm}$ x $1.5 \mathrm{~cm}$ ITO-coated glass slides ( $\leq 20 \Omega / \mathrm{sq}, \mathrm{PGO}$, Germany or (b) 1 $\mathrm{cm}$ x $1.5 \mathrm{~cm} \mathrm{Au}$ (vacuum deposited on glass slides over $3 \mathrm{~nm}$ of adhesion $\mathrm{Cr}$ layer; $50 \mathrm{~nm}$ Au layer) slides were used. Prior to usage, the ITO electrodes were subjected to a 10 minutes treatment in a plasma chamber. For all the electrochemical measurements a $0.1 \mathrm{M} \mathrm{CH}_{2} \mathrm{Cl}_{2}$ solution (Sigma Aldrich) with $\mathrm{n}-\mathrm{Bu}_{4} \mathrm{NPF}_{6}$ as supporting electrolyte (Sigma Aldrich) was employed; the electrolyte solution was deaerated through argon bubbling before the measurements. All potentials were referenced to the formal potential of the $\mathrm{Fc} \mid \mathrm{Fc}^{+}$intersolvental reference redox couple, measured in the same conditions of the analytes.

Electrochemical characterization of compounds 1 and 2 was performed on Au electrodes through cyclic voltammetry with sweep potentials between $-0.4-1.0 \mathrm{~V}$ vs $\mathrm{Fc} \mid \mathrm{Fc}^{+}$at a scan rate of $50 \mathrm{mV} \mathrm{s}^{-1}$, recording the voltammetric signal for 5 subsequent cycles. The voltammetric measurements were performed in a $0.5 \mathrm{mM}$ solution of the analyte in $0.1 \mathrm{M} \mathrm{n}-\mathrm{Bu}_{4} \mathrm{NPF}_{6} / \mathrm{CH}_{2} \mathrm{Cl}_{2}$.

Electrochemical deposition of Tetra-2 was performed under potentiodynamic conditions in the potential window $-0.69-0.69 \mathrm{~V}$ vs $\mathrm{Fc} \mid \mathrm{Fc}^{+}$with 10 subsequent voltammetric cycles at a scan rate of $50 \mathrm{mV} \mathrm{s}^{-1}$. For the oxidative electrodeposition of Tetra-2 films on ITO a $0.2 \mathrm{mM}$ monomer solution in $0.1 \mathrm{M} 0.1 \mathrm{M} \mathrm{n}$ $\mathrm{Bu}_{4} \mathrm{NPF}_{6} / \mathrm{CH}_{2} \mathrm{Cl}_{2}$ was employed. After the deposition, the electropolymerized films were rinsed with dichloromethane to remove the excess of monomer and electrolyte. For the determination of HOMO and 
LUMO energies, the electropolymerized films were repeatedly cycled in a monomer free solution ( $0.1 \mathrm{M} \mathrm{n-}$ $\mathrm{Bu}_{4} \mathrm{NPF}_{6} / \mathrm{CH}_{2} \mathrm{Cl}_{2}$; scan rate $\left.50 \mathrm{mV} \cdot \mathrm{s}^{-1}\right)$; with reduction $\left(-0.71-0.70 \mathrm{~V}\right.$ vs $\left.\mathrm{Fc} / \mathrm{Fc}^{+}\right)$and oxidation (-0.71 - $2.4 \mathrm{~V}$ vs $\mathrm{Fc} \mid \mathrm{Fc}^{+}$) cycles performed separately.

Thin-film in-situ spectroelectrochemical measurements (Tetra-2) were performed using an Autolab PGSTAT204 potentiostat (Metrohm) and a Zeiss UV-vis spectrometer endowed with a MCS621 Vis II spectrometer cassette and a CLH600F lamp or a Zeiss UV-vis-NIR spectrometer endowed with a MCS621 Vis II and a MCS611 NIR 2.2 $\mu$ spectrometer cassette and a CLH600F lamp. The measurements were conducted in a custom-made three-electrodes quartz cell employing a $\mathrm{Pt}$ wire as $\mathrm{CE}$, an $\mathrm{AgCl}$ coated $\mathrm{Ag}$ wire as (pseudo)reference electrode and the ep-Tetra-2 coated ITO as WE. The measurements were performed under Ar atmosphere and all the potential values were referenced to the formal potential of the $\mathrm{Fc} / \mathrm{Fc}^{+}$redox couple. In-situ spectroelectrochemical measurements were conducted with a scan rate of 20 $\mathrm{mV} \mathrm{s}^{-1}$ and potential steps of $10 \mathrm{mV}$, with simultaneous recording of electrochemical data points and UVVis spectra every $0.5 \mathrm{~s}$.

Thin-layer in-situ spectroelectrochemical measurements (chromophores 1 and 2) were performed due to the inability of the chromophores to be deposited as film on a working electrode. In-situ spectroelectrochemistry was measured in reflection mode in a quartz cell arranged for a three-electrode setup and employing a mirror type working electrode (WE) constituted by a polished Pt disk with a nominal diameter of $4 \mathrm{~mm}$. The WE was embedded in a glass holder connected to a micrometer screw which is used for adjusting the distance between cell bottom and WE. A platinum wire wrapped around the glass embedment is used as counter electrode (CE); a silver wire is used as (pseudo)reference electrode (RE) and calibrated through the redox couple ferrocene/ferrocenium. Spectroelectrochemical measurements were performed using an Autolab PGSTAT204 potentiostat (Metrohm) and a Zeiss UV-Vis spectrometer endowed with a MCS621 Vis II spectrometer cassette and a CLH600F lamp. The solution absorption upon electrochemical polarization was measured from the difference of the emitted and reflected light from the working electrode surface. All measurements were performed in thin layer conditions (the screw was adjusted to have $20 \mu \mathrm{m}$ distance between the WE surface and the bottom of the quartz cell), employing 0.5 $\mathrm{mM}$ chromophore solutions in $0.1 \mathrm{M} \mathrm{n}-\mathrm{Bu}_{4} \mathrm{NPF}_{6} / \mathrm{CH}_{2} \mathrm{Cl}_{2}$.

\section{Acknowledgements}

We acknowledge Beatrice Omicienski and Yannic Gross from the Institute of Polymer Chemistry (University of Stuttgart) for technical support and discussions. The authors thank the MATRIX SFR of the University of Angers and particularly the ASTRAL and CARMA platforms for the characterization of organic compounds. The University of Isfahan is thanked for the PhD grant of A. H. The RFI LUMOMAT 
and the Région Pays de la Loire are thanked for the PhD grant of A.L. P.S.M. thanks the European Union's Horizon 2020 research and innovation program under Marie Sklodowska Curie Grant agreement No.722651 (SEPOMO). The work at the University of Málaga was funded by the MINECO (CTQ2015-66897) and Junta de Andalucía (P09-FQM-4708) projects. The authors thankfully acknowledge the computer resources, technical expertise and assistance provided by the SCBI (Supercomputing and Bioinformatics) centre of the University of Malaga.

\section{Conflict of Interest}

The authors declare no conflict of interest.

\section{Graphical Abstract}

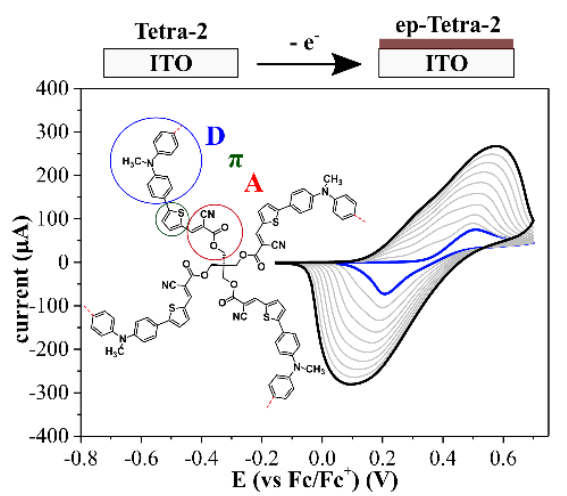

\section{References}

[1] P. Blanchard, C. Malacrida, C. Cabanetos, J. Roncali, S. Ludwigs, Polym. Int. 2019, 68, 589-606.

[2] Y. Shirota, H. Kageyama, Chem. Rev. 2007, 107, 953-1010.

[3] M. Thelakkat, Macromol. Mater. Eng. 2002, 287, 442-461.

[4] J. Roncali, P. Leriche, P. Blanchard, Adv. Mater. 2014, 26, 3821-3838.

[5] V. Malytskyi, J.-J. Simon, L. Patrone, J.-M. Raimundo, RSC Adv. 2015, 5, 354-397.

[6] X. Che, X. Xiao, J. D. Zimmerman, D. Fan, S. R. Forrest, Adv. Energy Mater. 2014, 4, 14005681400574.

[7] X. Che, Y. Li, Y. Qu, S. R. Forrest, Nat. Energy 2018, 3, 422-427.

[8] J. Min, Y. N. Luponosov, A. Gerl, M. S. Polinskaya, S. M. Peregudova, P. V. Dmitryakov, A. V. Bakirov, M. A. Shcherbina, S. N. Chvalun, S. Grigorian, et al., Adv. Energy Mater. 2014, 4, 
1301234-1301243.

[9] Y. Lin, P. Cheng, Y. Liu, X. Zhao, D. Li, J. Tan, W. Hu, Y. Li, X. Zhan, Sol. Energy Mater. Sol. Cells 2012, 99, 301-307.

[10] J. W. Choi, C.-H. Kim, J. Pison, A. Oyedele, D. Tondelier, A. Leliège, E. Kirchner, P. Blanchard, J. Roncali, B. Geffroy, RSC Adv. 2014, 4, 5236-5242.

[11] Y. Fedoryshyn, R. Cottier, C. Hoessbacher, C. Haffner, L. R. Dalton, D. L. Elder, A. F. Tillack, J. Leuthold, Y. Salamin, U. Koch, et al., Opt. Express 2017, 25, 2627.

[12] M. J. Cho, D. H. Choi, P. A. Sullivan, A. J. P. Akelaitis, L. R. Dalton, Prog. Polym. Sci. 2008, 33, 1013-1058.

[13] E. T. Seo, R. F. Nelson, J. M. Fritsch, L. S. Marcoux, D. W. Leedy, R. N. Adams, J Am Chem Soc 1966, 88, 3498-3503.

[14] O. Yurchenko, D. Freytag, L. Zur Borg, R. Zentel, J. Heinze, S. Ludwigs, J. Phys. Chem. B 2012, $116,30-39$.

[15] R. F. Nelson, R. N. Adams, J Am Chem Soc 1968, 90, 3925-3930.

[16] F. Edition, Organic Electrochemistry, Revised and Expanded, 2016.

[17] E. T. Seo, R. F. Nelson, J. M. Fritsch, L. S. Marcoux, D. W. Leedy, R. N. Adams, J. Am. Chem. Soc. 1966, 88, 3498-3503.

[18] H. J. Yen, G. S. Liou, Polym. Chem. 2018, 9, 3001-3018.

[19] N. Cocherel, P. Leriche, E. Ripaud, N. Gallego-Planas, P. Frère, J. Roncali, New J. Chem. 2009, $33,801-806$.

[20] K. Karon, M. Lapkowski, A. Dabuliene, A. Tomkeviciene, N. Kostiv, J. V. Grazulevicius, Electrochim. Acta 2015, 154, 119-127.

[21] M. Y. Chou, M. K. Leung, Y. O. Su, C. L. Chiang, C. C. Lin, J. H. Liu, C. K. Kuo, C. Y. Mou, Chem. Mater. 2004, 16, 654-661.

[22] S. H. Hsiao, J. W. Lin, Polym. Chem. 2014, 5, 6770-6778.

[23] T.-G. Sun, Z.-J. Li, J.-Y. Shao, Y.-W. Zhong, Polymers (Basel). 2019, 11, 73. 
[24] H. J. Yen, G. S. Liou, Polym. Chem. 2018, 9, 3001-3018.

[25] P. Reinold, K. Bruchlos, S. Ludwigs, Polym. Chem. 2017, 8, 7351-7359.

[26] E. J. W. Crossland, P. Cunha, S. Scroggins, S. Moratti, O. Yurchenko, U. Steiner, M. A. Hillmyer, S. Ludwigs, ACS Nano 2010, 4, 962-966.

[27] O. Yurchenko, J. Heinze, S. Ludwigs, ChemPhysChem 2010, 11, 1637-1640.

[28] A. Leliège, C.-H. Le Régent, M. Allain, P. Blanchard, J. Roncali, Chem. Commun. 2012, 48, 89078909.

[29] A. Leliège, J. Grolleau, M. Allain, P. Blanchard, D. Demeter, T. Rousseau, J. Roncali, Chem Eur J 2013, 19, 9948-9960.

[30] A. Labrunie, Y. Jiang, F. Baert, A. Leliège, J. Roncali, C. Cabanetos, P. Blanchard, RSC Adv. 2015, 5, 102550-102554.

[31] A. Labrunie, P. Josse, S. Dabos-Seignon, P. Blanchard, C. Cabanetos, Sustain. Energy Fuels 2017, $1,1921-1927$.

[32] Y. Jiang, C. Cabanetos, M. Allain, P. Liu, J. Roncali, J. Mater. Chem. C 2015, 3, 5145-5151.

[33] A. Labrunie, G. Londi, S. V. Dayneko, M. Blais, S. Dabos-Seignon, G. C. Welch, D. Beljonne, P. Blanchard, C. Cabanetos, Chem. Squared 2018, DOI 10.28954/2018.csq.10.001.

[34] E. V. Shklyaeva, O. A. Maiorova, I. V. Lunegov, A. N. Bakiev, D. G. Selivanova, G. G. Abashev, A. N. Vasyanin, A. A. Gorbunov, Chem. Heterocycl. Compd. 2016, 52, 379-387.

[35] L. Jin, B. Hu, Z. Liu, X. Zhang, M. Mo, C. Li, J. Electrochem. Soc. 2018, 165, 155-162.

[36] X. Ju, Q. Niu, Y. Hou, X. Liu, L. Kong, J. Zhao, Materials (Basel). 2016, 9, 779-795.

[37] D. Larumbe, I. Gallardo, C. P. Andrieux, J. Electroanal. Chem. Interfacial Electrochem. 1991, 304, 241-247.

[38] J. Hioe, D. Šakić, V. Vrček, H. Zipse, Org. Biomol. Chem. 2015, 13, 157-169.

[39] M. Moreno, C. P. Andrieux, J. Bertrán, I. Gallardo, D. Larumbe, J. Chem. Soc., Perkin Trans. 2 2004, $0,1437-1443$.

[40] R. F. Nelson, R. H. Philp, J. Phys. Chem. 1979, 83, 713-716. 
[41] A. Smie, A. Synowczyk, J. Heinze, R. Alle, P. Tschuncky, G. Götz, P. Bäuerle, J. Electroanal. Chem. 1998, 452, 87-95.

[42] P. Bäuerle, Adv. Mater. 1992, 4, 102-107.

[43] G. Engelmann, G. Kossmehl, J. Heinze, P. Tschuncky, W. Jugelt, H.-P. Welzel, J. Chem. Soc., Perkin Trans. 2 1998, 0, 169-176.

[44] J. Roncali, R. Garreau, A. Yassar, P. Marque, F. Garnier, M. Lemaire, J. Phys. Chem. 1987, 91, 6706-6714.

[45] P. Bäuerle, U. Segelbacher, A. Maier, M. Mehring, J. Am. Chem. Soc. 1993, 115, 10217-10223.

[46] R. J. Waltman, J. Bargon, Tetrahedron 1984, 40, 3963-3970.

[47] R. N. Adams, Acc. Chem. Res. 1969, 2, 175-180. 